\title{
SÁnchez Barrilao, Juan Francisco. Inteligencia y seguridad como objeto constitucional. El CNI y la comunidad de inteligen- cia ante los nuevos retos de la sociedad del riesgo, Centro de Estudios Políticos y Constitucionales, Madrid, 2019, 495 pp., ISBN 9788425918056.
}

http://dx.doi.org/10.18543/ed-67(2)-2019pp591-595

1. Es una estupenda noticia la aparición de la monografía que ahora comentamos, pues consideramos necesario que los constitucionalistas asumamos como objeto de estudio las cuestiones de seguridad y defensa. Tradicionalmente estaban situadas en otros predios del conocimiento. Sin embargo, la calidad democrática y nuestro sistema público se beneficiarán, sin duda, del interés que les prestemos a tales ámbitos desde el Derecho Constitucional, que completarán con la óptica específica de esa rama jurídica otro tipo de estudios.

No podemos dejar de reclamar, como ya hemos hecho en diversos foros, lo imperioso que resulta que sea el Derecho Constitucional el que ofrezca las respuestas primigenias a la multitud de retos y amenazas de seguridad que en el siglo XXI presionan a las sociedades en las que vivimos (así lo manifestamos, por ejemplo, en la presentación del congreso de la Asociación de Constitucionalistas de España de 2019, en Santiago de Compostela, dedicado a la «Seguridad y libertad en el Estado Democrático», presentación que se puede ver en http://tv.usc.es/mmobj/ index/file id/6584). Uno de los elementos imprescindibles que debe actuar en el análisis, detección y reacción ante los desafíos de seguridad es, sin duda, la actividad de inteligencia. Una actividad cuya importancia ha crecido de forma exponencial a medida que se complicaba la seguridad internacional y se desarrollaban entornos de conflicto híbrido, terrorismo de nuevo cuño, mutaciones geoestratégicas, recomposiciones geopolíticas o la irrefrenable irrupción de la tecnología. De este modo, la inteligencia se ve obligada a sofisticar sus actuaciones y métodos, incrementando recursos y actualizando estructuras. Además, la evolución del concepto de seguridad, integral, heterogéneo y poliédrico (acercándose a nuevas dimensiones, como la seguridad natural o la seguridad humana, más allá de la seguridad nacional o seguridad ciudadana), refuerza la relevancia de la inteligencia, tanto como proceso, como actividad o como organización. Un nuevo paradigma de la seguridad, con nuevos enfoques, que 
debe deslizar a su lado una inteligencia dinámica y compleja.

La toma de decisiones trascendentales, hoy en día, no puede realizarse sin inteligencia que aporte información analizada y depurada, la cual servirá para robustecer dicha toma de decisiones con un elemento preventivo inexcusable de cara al futuro. Y, al mismo tiempo, hay que reclamar en todo momento una inteligencia sometida al ordenamiento jurídico, rodeada de las pertinentes garantías para que esto siempre suceda.

2. El libro recensionado presenta cuatro grandes partes, precedidas de una introducción cuyo título es el del libro, lo que, precisamente, condensa parte de las ideas que acabo de exponer: la inteligencia y la seguridad como objeto constitucional. Con tales aseveraciones se sienta con firmeza una de las ideas clave de la obra, una idea que actúa al modo de predecisión de lo que después se desarrolla. Del mismo modo, también late como un postulado inicial la actual insuficiencia de la comunidad de inteligencia para afrontar la debilidad de los Estados ante la globalización, el desarrollo tecnológico y los riesgos.

La primera parte de la monografía se titula «Riesgo, seguridad, inteligencia y Derecho Constitucional». Se trata de un apartado heterogéneo, distanciado del resto, en el cual se parte de la sugerente idea de Ulrich Beck de sociedad del riesgo. Tal concepto aporta a nuestro autor la adecuada base epistemológica para desarrollar su discurso argumental. En este lugar también se efectúan unas reflexiones sobre el Derecho Constitucional de hoy, que necesita ir más allá de mera constitución normativa-estatal.
La segunda parte se dedica a repasar en nuestro país la organización de la inteligencia. El foco se centra en el Centro Nacional de Inteligencia (CNI), pero también se alude a otras entidades que conforman la comunidad de inteligencia, en el ámbito militar o policial, o en otros, como acertadamente también señala el autor. Asimismo, se incluye una referencia a nivel internacional y europeo. Parece que la creciente complejidad de la sociedad y del riesgo ha dado lugar a la propia parcelación y diversificación de la inteligencia como organización (en nuestro país destacan el CNI, el Centro de Inteligencia de la Fuerzas Armadas -CIFAS-, y el Centro de Inteligencia contra el Terrorismo y el Crimen Organizado -CITCO-). Tras estas descripciones se da un paso más para afirmar que el reto de la inteligencia integral pasa por la colaboración, cooperación y coordinación.

La parte tercera se refiere a la actividad de inteligencia, estructurada en cuatro capítulos. Se alude aquí, desde la óptica de la inteligencia, a las estrategias de seguridad; al terrorismo y al crimen organizado; a otros ámbitos de interés (protección civil, infraestructuras críticas, sistema económico y ciberseguridad); y a la inmigración y a la desafección constitucional. Esta parte revela la trascendencia que la inteligencia atesora en este siglo XXI. Su éxito será el éxito de la sociedad, de su progreso y estabilidad. Su debilidad será también la debilidad del sistema público. Atrás debe quedar una visión vetusta en este tema, que reducía la inteligencia a los servicios secretos.

El control de la inteligencia es objeto de la parte cuarta. Allí se abordan 
los temas del secreto y del control jurídico de la inteligencia, con especial referencia al CNI. La evolución del Estado en los últimos siglos reflejó el abandono de grandes parcelas de secreto en la actividad pública en favor de la publicidad. Sin embargo, permanecen relevantes zonas de secreto, sobre todo en el ámbito de la seguridad y la defensa, por lo que la cuestión sigue siendo polémica y necesitada de reformas legislativas. Además de ello, el control jurídico de la inteligencia presenta en España elementos propios, con un control judicial previo previsto en la Ley $11 / 2002$, de 6 de mayo, reguladora del CNI, y concretado en la LO 2/2002, de 6 de mayo.

La obra se cierra con unas consideraciones finales, que incluyen cuatro conclusiones y un epílogo. Las conclusiones se rotulan de forma clara, a saber: una inteligencia integral, pero cada vez más amplia y compleja; a más expansión del secreto, mayor déficit de control sobre la inteligencia; la necesidad de un régimen jurídico sobre la inteligencia; y hacia una seguridad e inteligencia integrada en Europa. El epílogo se refiere a la relación entre inteligencia, corrupción y democracia.

3. La obra es, sin duda, ambiciosa. Avanza movida por una correcta pluma y un adecuado empleo de los formantes jurídicos (el doctrinal, el normativo y el jurisprudencial). Este planteamiento lleva a abordar un elevado número de cuestiones, tal vez demasiadas, pero que se resuelven correctamente, con reflexión y espíritu crítico.

Por momentos pueden parecer excesivos los elementos descriptivos, referidos, por ejemplo, a temas organizativos. Sin embargo, consideramos oportuna tal forma de proceder pues la escasez de este tipo de trabajos en el ámbito de Derecho Público hace pertinentes tales aproximaciones descriptivas. Esto permitirá densificar nuestra base doctrinal y depurar los paradigmas y conceptos recibidos. El lector, por lo tanto, obtendrá elementos destacados para su formación y para la reconstrucción de una visión crítica del entendimiento actual de la seguridad.

Las páginas del texto propician el acercamiento entre la seguridad y la ciudadanía, que incluye un entendimiento ordinario y normalizado de la dinámica entre seguridad (e inteligencia) y libertad. Este éxito se consigue en la obra por el planteamiento sincero, valiente y sin prejuicios del que se hace gala en todo momento. El argumentario esgrimido discurre dentro de los límites y las exigencias del Estado Constitucional, lo que permite priorizar las garantías de los derechos fundamentales y la búsqueda de un control político y jurídico efectivo.

4. Las ideas-fuerza del libro poseen singular envergadura para el devenir que como sociedad democrática debemos articular en los próximos tiempos. Para ello se recurre, en varios momentos, a categorías que nos vienen de atrás, pero que debemos mantener operativas habida cuenta su carácter esencial en el Estado Democrático de Derecho.

En este sentido, el reto de la inteligencia integral es particularmente sugerente, pues así se podrán superar los problemas de los análisis parcelados o desconectados que impiden obtener las fortalezas propias de las actuaciones sinérgicas. Para ello es preciso institucionalizar la colaboración en 
inteligencia. En este sentido, el autor alude a un auténtico reto organizativo para que la inteligencia deje de ser «una mera red de nudos para transformarse en auténtica comunidad, pues ésta requiere de una mayor sistematización orgánica y funcional» (p. 164). $\mathrm{Y}$ he aquí donde aparece la necesidad de avanzar en la colaboración, cooperación y coordinación. Sólo de esta forma la inteligencia podrá adaptarse de forma permanente a la actual realidad tan compleja y cambiante. La cuestión de fondo es perseguir la eficiencia en esta actividad, que también verá así incrementada su legitimación. La razonabilidad del sistema total pasa por la regulación a través de ley y por una necesaria especialización material y funcional correctamente articulada que evite solapamientos. En esta línea se mira de igual forma a Europa, con el deseo de que se construya una auténtica seguridad europea, a cuyo servicio esté una inteligencia igualmente europea.

También debemos resaltar cómo, en varios lugares, se liga la cuestión de la inteligencia con distintos aspectos que podrían parecer alejados de ella, al tiempo que se señalan los efectos positivos que una correcta articulación de aquélla supondría para estos. Así, se habla de la desafección constitucional (pp. 324 y ss.) o de la corrupción (pp. 429 y ss.). El tema de la desafección constitucional se conecta con el auge de las ideologías extremistas y radicales, y con la difícil posición del sistema constitucional para enfrentarse a los desafíos que trae de la mano la globalización. En este sentido, se ve en el libro que no sólo estamos ante colectivos antisistema sino también ante grupos que usan y se integran en el sistema político pluralista. Esto es una amenaza para el pluralismo y para los derechos y libertades de la ciudadanía. La respuesta a esta problemática se hace acudiendo a categorías iuspublicistas de impronta germana, como la democracia militante, la lealtad o el patriotismo constitucionales. En el fondo, hay que afrontar una delicada paradoja, que esquematiza así Sánchez Barrilao: «la paradoja y el reto de cómo y hasta dónde puede un Estado controlar la calidad democrática ontológica en el ejercicio de derechos y libertades formalmente respetuosos del orden constitucional, y si en el control caben instrumentos de información e inteligencia públicas que permitan prevenir amenazas para la propia pervivencia (...) de la esencia constitucionalista del sistema político» (p. 331).

$\mathrm{Y}$ de igual forma, una de las cuestiones esenciales en la obra es un conjunto de propuestas de reforma normativa. En este sentido, se refiere a la recomendable modificación del régimen jurídico del secreto (sobre lo cual el autor también insiste en el núm. 44 de la revista Teoría y Realidad Constitucional). La Ley 9/1968, de 5 de abril, de secretos oficiales, sigue siendo la referencia clave en un tema que requiere de una vez por todas aggiornamento. En este sentido, sorprende la falta de coordinación de la Ley 19/2013, de transparencia, acceso a la información pública y buen gobierno, con la normativa de secretos oficiales. Además, la clasificación como secreto de una cuestión no debe significar inmunidad al control jurisdiccional (en esta línea está la STC 31/2014 -FJ 6-, que sigue la doctrina marcada por el 
TEDH en el caso de 1996 Chahal c. Reino Unido). El secreto no puede impedir per se el acceso efectivo a la tutela jurisdiccional. El llamado por Bobbio «poder invisible» no puede ser una coartada que mengüe un estándar aceptable de control.

En esta línea, también se reclama la reforma del control judicial previo del CNI, que se limita a las entradas en domicilios e intervenciones telefónicas, según establece la citada LO $2 / 2002$. Lo oportuno hubiera sido extender tal control, de igual forma, a otros derechos fundamentales. Aquí hay varias dificultades jurídicas de interpretación, como la difícil delimitación en actuaciones preventivas de los sujetos potenciales a los que se aplicarán medidas limitativas.

$\mathrm{Y}$, asimismo, se alude a la reforma general de la regulación de la inteligencia, lo que podríamos tildar como un paso necesario para avanzar en la sociedad democrática avanzada que se cita en nuestro preámbulo constitucional. Este cambio debería enfocarse como una lógica consecuencia de la actual extensión de la actividad de inteligencia. En idéntica línea el autor apunta que la seguridad requiere «no sólo de una profundización constitucional en su fundamentación», sino también de mayor «exigencia jurídiconormativa al penetrar en ámbitos especialmente delicados para los derechos y las libertades» (p. 423). En todo caso, los riesgos y amenazas debemos afrontarlos desde la normalidad constitucional, no desde la excepción, como también hace el autor siguiendo en parte a Ackerman (pp. 80 y ss.). Así se postulan estos cambios frente a las necesidades organizativas, funcionales y de control que manifiesta la inteligencia. Más en concreto, se cita la oportunidad de establecer un marco legal básico de la inteligencia española para su organización, actividad, intervención en derechos fundamentales, $\mathrm{y}$ control político y jurídico. El Derecho Comparado puede inspirar tal labor.

Al margen de lo dicho, otro elemento que estimamos destacado en el libro es la atención que se presta a los documentos estratégicos españoles, sobre todo a la vigente Estrategia de Seguridad Nacional, de 2017. Es habitual en el ámbito jurídico público no tener en consideración tales documentos, a pesar de la importancia práctica que tienen en el devenir del sistema público. Además, es una práctica habitual en la OTAN, que predetermina políticas públicas y compromisos en la escala internacional.

5. En fin, una obra de sumo interés, hecha con rigor y solvencia, en un tema que tendremos que seguir vigilando y analizando desde el Derecho Constitucional, abocados a la nueva dimensión que le aporta la llamada inteligencia estratégica y la ciberinteligencia. El futuro, si cabe, se nos muestra a los estudiosos como apasionante, aunque jalonado de dificultades. Este libro será una referencia imprescindible en tal esfuerzo.

\section{José Julio Fernández Rodríguez}

Profesor titular de Derecho Constitucional

Director del Centro de estudios de Seguridad (CESEG)

Universidad de Santiago de Compostela 


\section{SÁnchez Barrilao, Juan Francisco. Inteligencia y seguridad como objeto constitucional. El CNI y la comunidad de inteligen- cia ante los nuevos retos de la sociedad del riesgo, Centro de Estudios Políticos y Constitucionales, Madrid, 2019, 495 pp., ISBN 9788425918056.}

http://dx.doi.org/10.18543/ed-67(2)-2019pp591-595

\section{Copyright}

Estudios de Deusto es una revista de acceso abierto, lo que significa que es de libre acceso en su integridad. Se permite su lectura, la búsqueda, descarga, distribución y reutilización legal en cualquier tipo de soporte sólo para fines no comerciales, sin la previa autorización del editor o el autor, siempre que la obra original sea debidamente citada y cualquier cambio en el original esté claramente indicado

Estudios de Deusto is an Open Access journal which means that it is free for full access, reading, search, download, distribution, and lawful reuse in any medium only for non-commercial purposes, without prior permission from the Publisher or the author; provided the original work is properly cited and any changes to the original are clearly indicated. 